\section{Boring but important: the community mental health team}

Green and Gowans are right to worry about what has happened to the seriously mentally ill when the number of psychiatric beds has been mercilessly cut. ${ }^{1}$ However, it may be misleading when they talk of 'a lack of evidence for community teams' and then talk about crisis teams (CTs). The fact that CTs - often heralded as 'the' alternative to admission - perform poorly under scrutiny $^{2}$ does not mean that community care is by necessity poor.

The rise of the so-called functional teams $-C T$, assertive outreach (AO), early intervention for psychosis - has not led to great (or at least greatly demonstrable) advantages for patients. A particularly salutary tale comes from the work of Killaspy et al. ${ }^{3}$ They used the community mental health team (CMHT) as treatmentas-usual comparator for an intensive case management model, the $\mathrm{AO}$ team. But be careful what the placebo is. While briefer follow-up looked promising, ${ }^{4}$ this longer follow-up eventually found $\mathrm{AO}$ to do scarcely better than the CMHT for a lot more clinical effort and presumably, cost. $^{3}$ Early intervention for psychosis services, too, have had questionable benefits. ${ }^{5}$

All of this could, and should, be seen as evidence of the value of generic boring-butimportant community mental health care on the district psychiatry model. ${ }^{6}$ The CMHT suffers from having come into the world essentially before the era of the randomised controlled trial, but some other research also indicates its usefulness among even the most severely ill long-stay patients.?

The authors here hint at a problem at the other side of the hospitals, acute presentation, which may explain their focus on CTs. ${ }^{1}$ When justly lamenting the increasingly poor provision of inpatient care for the most mentally ill in our society, though, it is as well to talk of the tangible relative success of the CMHT rather than the straw man of the CT.

Alasdair Forrest,

CT2 in Psychiatry, Parkhead Hospital, Glasgow.

\section{E-mail: alasdair.forrestlanhs.net}

\section{REFERENCES}

1. Green B, Gowans WJ. Mental health care in hospitals and primary care: an unsustainable balance. Br J Gen Pract 2015; DOI: 10.3399/ bjgp15X683365

2. Murphy S, Irving CB, Adams CE, Driver R. Crisis intervention for people with severe mental illnesses. Cochrane Database Syst Rev 2012; 5: CD001087.

3. Killaspy $\mathrm{H}$, Kingett $\mathrm{S}$, Bebbington $\mathrm{P}$, et al. Randomised evaluation of assertive community treatment: 3-year outcomes. Br J Psychiatry 2009; 195(1): $81-82$.

4. Killaspy $\mathrm{H}$, Bebbington $\mathrm{P}$, Blizard R, et al. REACT: a randomised evaluation of assertive community treatment in North London. BMJ 2006; 332(7545): 815-819

5. Pelosi AJ. Rational policy making for early psychosis might yet become possible. BMJ 2012; 344: e3137.

6. Burns T. End of the road for treatment-as-usual studies? Br J Psychiatry 2009; 195(1): 5-6.

7. Leff J, Trieman N. Long stay patients discharged from psychiatric hospitals: social and clinical outcomes after five years in the community: the TAPS project 46. Br J Psychiatry 2000; 176: 217-233.

DOI: 10.3399/bjgp15X684313

\section{Invest in community- based solutions that address individuals' needs: not more beds}

Green and Gowans ${ }^{1}$ discuss the balance between the community and inpatient care of patients with mental health problems. They provide an analysis of resource allocation in mental health care with which I fundamentally disagree. Their core proposal is for more investment in psychiatric beds, with the possibility of improved primary care mental health as an afterthought. In contrast I suggest that a continued shift in investment towards community-based care is required, but with general practice and the third sector playing strong core roles. Within the confines of a limited NHS budget, following 3 years of decline down to $13 \%$, I concur with others that a higher share goes to mental health care. ${ }^{2}$
While I agree with Green and Gowans that reductions in psychiatric bed availability have driven the reduction in admissions, there has been considerable investment in home treatment/crisis teams to support the policy. ${ }^{3}$ In contrast to many policies directing reorganisation of services there is relatively good evidence that home treatment teams can support individuals to stay safely out of hospital and provide a better experience of care during a crisis. ${ }^{4}$ While practice is highly variable, and this needs addressing, I have witnessed first-hand the benefits of a well-functioning crisis team and inpatient acute care system. Analyses of admission decisions also suggest that many inpatient stays are not necessary. ${ }^{5}$ The problem is likely to lie in implementation and a risk averse culture in the NHS.

While we need to optimise our response to crises, it is possibly more important to focus on generating positive outcomes; there are a range of community-based interventions, such as early intervention for psychosis, smoking cessation, and support into work which are likely to be cost-effective. ${ }^{3}$ Community-based mental health services need to be able to perform three interlinked key functions, and general practice has a role to play in each:

- promoting better mental health and social outcomes, such as feelings of resilience, hope and wellbeing; having a home, and being in work;

- proactively managing specific short and longer term mental health problems, such as bouts of depression with anxiety, relapsing post-traumatic stress disorder with comorbid substance use, and the physical health needs of individuals with psychosis and dementia; and

- anticipating and responding to crises.

I suggest that future research should not be centred primarily around the epidemiology of the current inherently flawed diagnostic classification system, as implied by Green and Gowans, but should instead focus on understanding individuals' needs for services lalong with their strengths and resources). Patients personal goals, the links between their individual patterns of emotion, thinking, behaviour, and social situation define the services that are needed. Alongside selfmanagement, carers, and family, resources 
in the community, third-sector and statutory organisations, can all contribute.

For general practice and primary care this will certainly require different training and more resources. The experience for all could be quite different: an individual with 'stress' booking straight into their choice of groups run by Improving Access to Psychological Therapies (IAPT) services; a patient with psychosis booking their follow up with the practice-based community psychiatric nurse through GP receptionists; a third-sector practitioner liaising with a GP to discuss the mutually accessible online shared plan for an individual with psychosis; a GP calling a psychiatrist to discuss reducing doses of antipsychotic medication for a patient the psychiatrist had seen as a one off at the practice; the practice-based IAPT practitioner providing cognitive behavioural therapy for anxiety as part of the aftercare plan following community-based alcohol detoxification. All possible with a small shift in allocation of NHS resources.

\section{Richard Byng,}

Professor in Primary Care Research and GP with a Special Interest in Mental Health, Plymouth University, Plymouth. E-mail: richard.bynglaplymouth.ac.uk

\section{REFERENCES}

1. Green B, Gowans WJ. Mental health care in hospitals and primary care: an unsustainable balance. Br J Gen Pract 2015; DOI: 10.3399/ bjgp15X683365

2. The Mental Health Policy Group. A manifesto for mental health. 2015. http://wnw.mentalhealth.org. uk/content/assets/PDF/publications/manifestobetter-mental-health.pdf (accsessed 4 Mar 2015).

3. Knapp M, Andrew A, McDaid D, et al. Investing in recovery: making the business case for effective interventions for people with schizophrenia and psychosis. Rethink Mental Illness. 2014. http://wnw. rethink.org/media/1030280/investing_in_recovery. pdf (accsessed 4 Mar 2015).

4. Murphy S, Irving CB, Adams CE, Driver R. Crisis intervention for people with severe mental illnesses. Cochrane Database Syst Rev 2012; 5: CD001087.

5. Stanton E, Baggaley M. Are mental health patients getting the right treatment? Results from a comprehensive review of patient notes. 2012. http:// beaconhs.co.uk/wp-content/uploads/2015/02/ beacon-uk-assessing-mental-healthcare.pdf (accsessed 4 Mar 2015).

DOI: 10.3399/bjgp15X684325

\section{Digital mental health services in general practice}

Claire Harding and colleagues have highlighted the potential of digital interventions in general practice and the need for NHS accredited or 'kitemarked' apps, but also raise questions about the need for evidence of their safety and efficacy. ${ }^{1}$

They state that '... there is broad consensus in the field that traditional randomised controlled trials are not fit for purpose with digital interventions llargely because services develop and expectations change faster than trials can be run) .... We acknowledge that good interventions take time to develop and test, but do not agree that this is a reason to abandon evidencebased practice. Users and commissioners should expect robust evidence before choosing to invest time or resources in such interventions.

For simple health information on the web, common sense 'kitemarking' may be sufficient. However, for interventions aimed at behaviour change, randomised controlled trials are warranted, regardless of whether they are delivered digitally. Rapid changes in services are not sufficient reason to negate this necessity, as welldeveloped interventions can be adapted to new delivery systems.

Miriam Santer,

Clinical Lecturer, University of Southampton, Southampton. E-mail: m.santerlasoton.ac.uk
Hazel Everitt,

Clinical Lecturer, University of Southampton, Southampton.

\section{REFERENCE}

1. Harding $C$, Ilves $P$, Wilson S. Digital mental health services in general practices. Br J Gen Pract 2015 DOI: 10.3399/bjgp15X683377.

DOI: 10.3399/bjgp15X684337

\section{Endometriosis in secondary care}

As a hospital gynaecologist I may not be the best person to comment on your article but these are my thoughts. Symptoms that could be due to endometriosis are extremely common in both primary care and the hospital gynaecology clinic. With the exception of women who are currently trying to conceive, it is perfectly reasonable to treat these symptoms hormonally. The earlier Royal College of Obstetricians and Gynaecologists guideline as well as the more recent European guideline you quote, both recommend treating symptoms with either the combined contraceptive pill, an ovulation suppressing progesterone-only pill, or the Mirena ${ }^{\circledR}$ interauterine system. Women referred to hospital because of the supposed importance of early diagnosis may be disappointed to be offered precisely those treatments if they attend a consultant clinic.

Stewart Pringle,

Consultant Gynaecologist, South Glasgow University Hospitals, Glasgow.

E-mail: stewartpringleanetscape.net

\section{REFERENCE}

1. Johnston JL, Reid H, Hunter D. Diagnosing endometriosis in primary care: clinical update. $\mathrm{Br}$ J Gen Pract 2015; DOI: 10.3399/bjgp15X683665.

DOI: 10.3399/bjgp15X684349 